\section{Dalton, John}

T. Arndt

Bioscientia Institut für Medizinische Diagnostik $\mathrm{GmbH}$, Ingelheim, Deutschland

Lebensdaten Englischer Naturforscher und Lehrer, geb. am 06. September 1766 in Eaglesfield (England), gest. am 27. Juli 1844 in Manchester.

Verdienste Dalton war bereits mit 12 Jahren Lehrer an einer Quaker-Schule. Er und sein Bruder waren farbenblind. Entdeckt die genetische Verankerung der Rot-Grün-Blindheit. Bestimmt gleichzeitig mit Gay-Lussac den Ausdehnungsko- effizienten der Gase. Beschreibt 1804 das Gesetz der multiplen Proportionen, 1807 das Gesetz vom Partialdruck der Gase. Entwicklung der nach ihm benannten Atomhypothese (1805), die erst nach gut 100 Jahren in ihren letzten Konsequenzen bestätigt werden konnte.

- Dalton (Abkürzung Da oder D) ist eine nach John Dalton benannte, nicht SI-konforme Einheit, die dennoch gewöhnlich für Angaben zur Molmasse von hochmolekularen Verbindungen wie Peptiden und Proteinen verwendet wird.

\section{Literatur}

https://www.biography.com/people/john-dalton-9265201. Zugegriffen am 04.09.2017 